\title{
Syphilis and HIV prevalence and associated factors to their co-infection, hepatitis B and hepatitis $C$ viruses prevalence among female sex workers in Rwanda
}

Mwumvaneza Mutagoma ${ }^{1,2^{*}}$, Laetitia Nyirazinyoye ${ }^{2}$, Dieudonné Sebuhoro ${ }^{1}$, David J. Riedel ${ }^{3}$ and Joseph Ntaganira ${ }^{2}$

\begin{abstract}
Background: Human Immunodeficiency Virus (HIV), syphilis, Hepatitis B Virus (HBV) and Hepatitis C Virus (HCV) are sexually transmitted infections (STIS) and share modes of transmission. These infections are generally more prevalent among female sex workers (FSWs).

Methods: This is a cross-sectional study conducted among female sex workers (FSWs) in Rwanda in 2015. VenueDay-Time (VDT) sampling method was used in recruiting participants. HIV, syphilis, HBV, and HCV testing were performed. Descriptive analyses and logistic regression models were computed.

Results: In total, 1978 FSWs were recruited. The majority (58.5\%) was aged between 20 and 29 years old. Up to 63. 9\% of FSWs were single, $62.3 \%$ attained primary school, and $68.0 \%$ had no additional occupation beside sex work. Almost all FSWs (81.2\%) had children. The majority of FSWs (68.4\%) were venue-based, and most (53.5\%) had spent less than five years in sex work. The overall prevalence of syphilis was 51.1\%; it was 2.5\% for HBV, 1.4\% for HCV, 42. 9\% for HIV and 27.4\% for syphilis/HIV co-infection. The prevalence of syphilis, HIV, and syphilis + HIV co-infection was increasing with age and decreasing with the level of education. A positive association with syphilis/HIV co-infection was found in: 25 years and older ( $\mathrm{aOR}=1.82$ [95\% Cl:1.33-2.50]), having had a genital sore in the last 12 months ( $\mathrm{aOR}=1.34$ [95\% Cl:1.05-1.71]), and having HBsAg-positive test (aOR = 2.09 [1.08-4.08]).

Conclusion: The prevalence of HIV and syphilis infections and HIV/syphilis co-infection are very high among FSWs in Rwanda. A strong, specific prevention program for FSWs and to avert HIV infection and other STIs transmission to their clients is needed.
\end{abstract}

Keywords: Female sex workers, HIV, Syphilis, HBV, HCV, Co-infection, Rwanda

\section{Background}

Human Immunodeficiency Virus (HIV), syphilis, Hepatitis B Virus (HBV) and Hepatitis C Virus (HCV) are sexually transmitted diseases (STIs) and have shared modes of transmission. Female sex workers (FSWs) are at high risk to contract STIs due to the work and their behavior $[1,2]$. The World Health Organization (WHO) reported that the global prevalence of HIV among FSWs was $11.8 \%$ with

\footnotetext{
*Correspondence: mutagoma@gmail.com

${ }^{1}$ Rwanda Biomedical Centre, Ministry of Health, P. O. Box, 7162 Kigali, Rwanda

${ }^{2}$ University of Rwanda, College of Medicine and Health Sciences, School of Public Health, Kigali, Rwanda

Full list of author information is available at the end of the article
}

significant variation by region, with the highest prevalence found in sub-Saharan Africa with an aggregated prevalence of $36.9 \%$ [3]. The prevalence of HIV among FSWs is 10-20-fold higher than the general population in many African countries [4].

A meta-analysis study conducted in African countries found that the HIV prevalence among FSWs varied between 19\% and 60\% [5]. Despite the control of HIV among the general population in Rwanda (3.0\%) [6], STIs are still a concern among FSWs. In 2011 a $24.0 \%$ prevalence of HIV was estimated among FSWs in Kigali, Rwanda [7] which was three times higher than the 
prevalence of HIV in the general population in the same city $(7.3 \%)[8]$ in the same period.

WHO reported that 10 countries had greater than $10 \%$ syphilis prevalence among sex workers, while some countries reported a syphilis prevalence of more than $20 \%$ [1]. A low prevalence of syphilis among FSWs was reported in few African countries. In Somaliland, the prevalence of syphilis was 3.1\% [9], and 3.3\% among FSWs in Kisumu, Kenya [10]. A high prevalence of syphilis among FSWs was reported in other countries for example, it was $21.0 \%$ in Kampala, Uganda [11] and $52.4 \%$ in Addis Ababa, Ethiopia [12] in two separate cross-sectional studies.

Few data about HCV and HBV among FSWs have been published. WHO estimated the worldwide number of people living with chronic HCV between 130 and 150 million [13] while this number was estimated at 240 million of people chronically infected with hepatitis B [13]. In China, the prevalence of $\mathrm{HCV}$ was estimated at $0.8 \%$ in one province [14] and $1.1 \%$ in another province [15], it was $2.8 \%$ in India [16].

The prevalence of $\mathrm{HBV}$ in India was estimated at $7.6 \%$ [17] while it was $17.1 \%$ in Nigeria [17].

The interaction between syphilis and HIV is not well documented [18]. Syphilis as an ulcerative infection, increases HIV transmission. Syphilis in clinically immunosuppressed HIV-infected patients is reported to be associated with greater organ involvement [19]. In Nepal the proportion of syphilis and HIV co-infection was $31.0 \%$ [20]. Factors such as STIs symptoms, lower level of education were described being positively associated with syphilis and HIV infections [21].

Currently, few data are published on HBV and HCV among FSWs in Rwanda. A study conducted in 2013 found that the prevalence of HBV was $1.6 \%$ among blood donors, while the prevalence of $\mathrm{HCV}$ was $2.9 \%$ among health workers [22]. A meta-analysis of studies from sub-Saharan Africa reported an HBV prevalence of $4.1 \%$ and an HCV prevalence of $2.1 \%$ among HIVinfected persons [23].

The aim of this study is to describe the burden of syphilis, HIV, HBV, HCV and HIV/syphilis co-infection and associated factors among FSWs in Rwanda.

\section{Methods}

\section{Study setting and population}

This study was a cross-sectional behavioral and biological survey among FSWs in Rwanda in 2015. VenueDay-Time (VDT) sampling method was used to identify specific places and times where FSWs await their subsequent sexual clients [24]. The time frame was determined by the peak hours of the presence of FSWs at hot spots.
Before the data collection process, a rapid assessment to estimate the number of expected FSWs was conducted. The number of FSWs at each site was estimated by key informants selected in the same target population. The survey was conducted in all hot spots with 5 or more FSWs per day. The number of participants recruited in each hot spot was determined using probability proportional to size of each selected site.

\section{Population and inclusion criteria}

Self-reported FSW aged 15 years or more found in a FSW hot spot area identified by a FSW key informant was eligible to participate. Excluded from the survey were: FSWs less than 15 years old, not self-identifying as a female sex worker, declining to consent to participate in the survey.

\section{Sampling}

A two-stage sampling method using VDT sampling, referring to the specific peak time and place that FSWs were present at their hot spot was used. The primary sampling unit was the time and place where FSWs were present at the hotspot, and the secondary sampling unit was FSWs in the selected time and place. A "take-all" approach sampling was used. Once the expected sample size at the site was obtained, data collection was closed at that site. For primary sampling unit (PSU) selection, 180 hotspots were selected from the sampling frame in the country.

\section{Sample size calculation}

The sample size calculation used the $\mathrm{Z}$ score value of 1.96 with an alpha level of 0.05 (95\% confidence), the design effect of 3.2 , a relative $10 \%$ precision around a point estimate (HIV prevalence) of $51 \%$ among female sex workers in 2010. A minimum sample size of 1980 FSWs was calculated.

\section{Data collection methods}

FSWs were contacted by data collectors to take part in the survey. If eligible, a verbal informed consent was administered with no identifying information. After verbal consent was received, pre-test counselling was conducted by a nurse counsellor. The laboratory technician drew blood by venipuncture. A Personal Digital Assistant (PDA) questionnaire was administered by survey staff. Rapid diagnostic test results were returned to the participant and post-test counselling was conducted in few minutes. Participants whose test was positive for HIV, syphilis, HBV or HCV were referred to the health centre of the patient's choice for clinical care. Blood samples were transported to the National Reference Laboratory (NRL) for confirmatory HIV testing for survey purposes. 


\section{HIV testing}

HIV rapid testing was performed by a trained laboratory technician using the nationally approved algorithm of three serial rapid tests (currently approved protocol: Shanghai-Kehua, Determine, and Uni-Gold). For the survey purpose, ELISA-based testing was used (Vironostika ${ }^{\bullet}$ HIV Uni-form II Ag/Ab, 4th Generation) for all samples. For samples testing positive with ELISA, a confirmatory test used a second EIA called Murex HIV Ag/Ab Combination 4th Generation Murex ${ }^{\oplus}$

\section{Syphilis testing}

Screening for syphilis was conducted on site using the SD BIOLINE SYPHILIS 3.0 rapid test to detect syphilis anti-bodies. A reacting sample was retested using the RPR test at NRL. A sample that was positive for both tests was recorded as positive; a non-reacting sample to the second test was recorded as negative.

\section{Hepatitis B testing}

Screening for HBV was performed using the SD BIOLINE HBV rapid test to detect HBV surface antigen (HBsAg). A reacting sample was recorded as positive.

\section{Hepatitis C testing}

Screening for HCV was performed using the SD BIOLINE HCV rapid test. The test detected HCV antibody (anti-HCV). A reacting sample was recorded as positive.

All FSWs with positive tests for any test were transferred to the nearest health facility or the health facility of their choice in order to provide quick results for clinical care.

\section{Data analysis}

STATA 13 software was used for data analysis. Mean, proportion, and 95\% confidence interval were computed for descriptive analysis of variables. Prevalence in different socio-demographic characteristics was estimated for HIV, syphilis, HBV, HCV infections and for HIV and syphilis co-infection.

HIV and syphilis co-infection associated factors significant at the $p<0.05$ level in bivariate analysis were included in a multivariable logistic regression model. Multivariable analysis was computed to determine the effect of independent variables to HIV and syphilis coinfection. Variables were retained in the final model when achieving $p<0.05$ significance.

\section{Results}

Table 1 displays the description of respondents in the survey. In total, 1978 FSWs participated in the survey. The median age was 26 years old (Interquartile Range [IQR] 22,31). The majority (58.5\%) was aged between 20 and 29 years old. Up to $63.9 \%$ of FSWs were single and
$30.0 \%$ were either divorced or separated. A majority (68.4\%) of FSWs were recruited in and around venues (e.g. bars, night clubs, and hotels). About formal education, 62.3\% attained primary school. Most FSWs (68.0\%) had no other occupation beside sex work. The majority (56.4\%) of FSWs had health insurance. Almost all FSWs (81.2\%) had children; the average number of children per participant was two. The average monthly income was Rwf 40,549.0 (\$50.20).

Table 2 displays the prevalence of RPR, HBsAg, HCV $\mathrm{Ab}, \mathrm{HIV}$ positive tests and syphilis and HIV co-infection. The overall prevalence of RPR-positive test among FSWs was $51.1 \%$. This prevalence was increasing with age up to 29 years old. It was $42.9 \%$ [95\% CI:36.0-49.9] in 1519 years age group and 55.5\% [95\% CI:51.3-59.7] among 25-29 years age group. There was no significant difference in prevalence of RPR-positive test by marital status. The western (58.6\% [95\% CI:53.3-64.0]) and southern provinces (58.8\% [95\% CI:50.4-61.2]) had higher RPRpositive prevalence than the North(44.2\% [39.3-49.2]). The prevalence of RPR-positive test was significantly decreasing with the level of education: it was $66.3 \%$ [95\% CI:61.3-71.2], 51.9\% [95\% CI:49.1-54.7] and $34.9 \%$ [95\% CI:30.1-39.6], respectively, in none, primary and secondary/higher education levels. RPRpositivity was increased with the duration of sex work: $47.8 \% \quad[95 \%$ CI:44.7-50.8] and 54.9\% [95\% CI:51.3-58.5], respectively, among FSW with $0-5$ years and 6-15 years of duration of sex work.

The prevalence of HBsAg-positive test among FSWs was $2.5 \%$ [95\% CI:1.8-3.2]; the prevalence of HCAbpositive test among FSWs was 1.4\% [95\% CI:0.8-1.9].

The overall prevalence of HIV was $42.9 \%$ [95\% CI:39.5-43.8]. This prevalence was increasing with age up to 34 years old. It was $22.3 \%$ [95\% CI:16.5-28.2] among FSWs 15-19 years age group while it was more than two times higher among FSWs with 30-34 years old. The HIV prevalence was higher among divorced or separated $(47.3 \% \quad[95 \%$ CI:43.2-51.3]) and widowed (59.4\% [95\% CI:49.7-69.1]) compared to single (37.5\% [95\% CI:34.9-40.2]) FSWs. By province, the highest prevalence of HIV was in the city of Kigali (54.3\% [95\% CI:48.5-60.0]), the lowest was found in the Eastern province (36.3\% [95\% CI:32.6-40.0]). The prevalence of HIV was significantly decreasing with the level of education. It was $52.6 \%\left[\begin{array}{lll}95 \% & \mathrm{CI}: 34.5-44.9], & 42.1 \%\end{array}[95 \%\right.$ CI:39.3-44.9] and 30.3\% [95\% CI:25.7-34.9] respectively in none, primary and secondary/higher education levels. The prevalence of HIV was significantly increasing with the duration of sex work. It was $33.7 \%$ [95\% CI:30.8-36.6], 47.8\% [95\% CI:44.1-51.4] and 61.0\% [95\% CI:53.3-68.7] respectively among FSW with 05 years, 6-15 and more than 16 years of duration of sex work (Table 2). 
Table 1 Background characteristics among sex workers, 2015 Rwanda

\begin{tabular}{|c|c|c|}
\hline Characteristics & Number & Percent \\
\hline Total & 1978 & 100 \\
\hline Median age & 26 & \\
\hline \multicolumn{3}{|l|}{ Age group 1} \\
\hline $15-19$ & 198 & 10.0 \\
\hline $20-24$ & 618 & 31.3 \\
\hline $25-29$ & 538 & 27.2 \\
\hline $30-34$ & 360 & 18.2 \\
\hline $35-39$ & 159 & 8.1 \\
\hline $40+$ & 102 & 5.2 \\
\hline \multicolumn{3}{|l|}{ Age group 2} \\
\hline $15-24$ & 816 & 41.3 \\
\hline $25+$ & 1159 & 58.7 \\
\hline \multicolumn{3}{|l|}{ Current marital status } \\
\hline Single & 1263 & 63.9 \\
\hline Married/cohabitating & 19 & 1.0 \\
\hline Divorced/Separated & 594 & 30.0 \\
\hline Widow & 102 & 5.2 \\
\hline \multicolumn{3}{|l|}{ Province } \\
\hline East & 646 & 32.7 \\
\hline Kigali city & 293 & 14.8 \\
\hline North & 389 & 19.7 \\
\hline West & 324 & 16.4 \\
\hline South & 326 & 16.5 \\
\hline \multicolumn{3}{|l|}{ Hotspot type } \\
\hline Road/public place & 625 & 31.6 \\
\hline Venue-based & 1353 & 68.4 \\
\hline \multicolumn{3}{|l|}{ Level of education } \\
\hline None & 353 & 17.9 \\
\hline Primary & 1231 & 62.3 \\
\hline Secondary/Higher & 394 & 19.9 \\
\hline \multicolumn{3}{|l|}{ Religion } \\
\hline Catholic & 775 & 39.2 \\
\hline Protestant & 584 & 29.5 \\
\hline Muslin & 164 & 8.3 \\
\hline Adventist & 186 & 9.4 \\
\hline Traditional/Other/No religion & 269 & 13.6 \\
\hline \multicolumn{3}{|l|}{ Occupation } \\
\hline Sex work only & 1345 & 68.0 \\
\hline Sex work with additional occupation & 633 & 32.0 \\
\hline \multicolumn{3}{|l|}{ Additional occupation } \\
\hline Small business at the market & 94 & 4.8 \\
\hline Job in a bar & 51 & 2.6 \\
\hline Street vendor & 113 & 5.7 \\
\hline
\end{tabular}

Table 1 Background characteristics among sex workers, 2015 Rwanda (Continued)

\begin{tabular}{lll}
\hline Job in a restaurant & 10 & 0.5 \\
House worker & 22 & 1.1 \\
Handicraft maker & 23 & 1.2 \\
Dressmaker & 13 & 0.7 \\
Hairdresser & 41 & 2.1 \\
Student & 3 & 0.2 \\
Other occupations & 299 & 15.1 \\
Had a valid health insurance & & \\
Yes & 1116 & 56.4 \\
Had children & & \\
Yes & 1607 & 81.2 \\
Duration of sex work & & \\
0-5 & 1036 & 53.5 \\
$6-15$ & 741 & 38.3 \\
16+ & 159 & 8.2 \\
\hline
\end{tabular}

The prevalence of syphilis/HIV co-infection among FSWs was 27.4\% [95\% CI:25.4-29.4] while the proportion of RPR-positive test among HIV-positive was $69.2 \%$ [95\% CI:66.1-72.4] and the proportion of HIV-positive among RPR-positive test was 56.4\% [95\% CI:53.3-59.5]. The prevalence of syphilis/HIV co-infection among FSWs increased with age up to 34 years old. It was 13.0\% [95\% CI:8.2-17.7] among FSWs 15-19 years age group and it was more than three times higher among FSWs 30-34 years 39.3\% [95\% CI:34.1-44.4]. The city of Kigali had the highest prevalence of syphilis and HIV coinfection (35.7\% [95\% CI:30.1-41.2]) compared to the Eastern and the Northern provinces with respectively (21.6\% [95\% CI:18.4-24.8]) and 21.7\% [95\% CI:17.625.8]. By level of education the prevalence of syphilis and HIV co-infection decreased with the level of education. It was $37.5 \%$ [95\% CI:34.5-44.9], 27.7\% [95\% CI:25.1-30.2] and 15.7\% [95\% CI:12.0-19.4] respectively in none, primary and secondary/higher education levels. The prevalence of syphilis and HIV co-infection increased with the duration of sex work. It was $21.7 \%$ [95\% CI:19.2-24.3] and 32.6\% [95\% CI:29.2-36.1] respectively among FSWs with $0-5$ years and $6-15$ years duration of sex work (Table 2).

In bivariable logistic regression, age 25 years or older, being ever married, having more than five years of duration of sex work, having children, having had genital sores in the last 12 months, and having HBsAg positive test were positively associated with syphilis and HIV coinfection, whereas secondary or high education level was negatively associated with syphilis and HIV co-infection (Table 3). 
Table 2 Syphilis, HBV, HCV and HIV prevalence and HIV co-infection among FSW in Rwanda, 2015

\begin{tabular}{|c|c|c|c|c|c|c|c|c|c|c|}
\hline \multirow[t]{2}{*}{ Characteristics } & \multicolumn{2}{|c|}{ Syphilis } & \multicolumn{2}{|c|}{ HBV } & \multicolumn{2}{|c|}{$\mathrm{HCV}$} & \multicolumn{2}{|l|}{ HIV } & \multicolumn{2}{|c|}{ Syphilis and HIV co-infection } \\
\hline & $n$ & $\%[95 \% \mathrm{Cl}]$ & $n$ & $\%[95 \% \mathrm{Cl}]$ & $n$ & $\%[95 \% \mathrm{Cl}]$ & $n$ & $\%[95 \% \mathrm{Cl}]$ & $n$ & $\%[95 \% \mathrm{Cl}]$ \\
\hline Overall & 1010 & $51.1[48.9-53.3]$ & 50 & $2.5[1.8-3.2]$ & 28 & $1.4[0.8-1.9]$ & 819 & $42.9[39.5-43.8]$ & 528 & $27.4[25.4-29.4]$ \\
\hline \multicolumn{11}{|l|}{ Age group } \\
\hline $15-19$ & 85 & $42.9[36.0-49.9]$ & 6 & $3.0[0.6-5.4]$ & 3 & $1.5[0.2-3.2]$ & 49 & $22.3[16.5-28.2]$ & 25 & $13.0[8.2-17.7]$ \\
\hline $20-24$ & 292 & $47.3[43.3-51.2]$ & 12 & $1.9[0.8-3.0]$ & 6 & $1.0[0.2-1.7]$ & 213 & $32.7[29.0-36.4]$ & 129 & $21.3[18.0-24.6]$ \\
\hline $25-29$ & 298 & $55.5[51.3-59.7]$ & 12 & $2.2[1.0-3.5]$ & 3 & $0.6[0.1-1.2]$ & 243 & $43.2[38.9-47.4]$ & 148 & $28.5[24.6-32.4]$ \\
\hline $30-34$ & 198 & $55.0[49.8-60.2]$ & 14 & $3.9[1.9-5.9]$ & 5 & $1.4[0.2-2.6]$ & 195 & $55.0[49.8-60.2]$ & 137 & $39.3[34.1-44.4]$ \\
\hline $35-39$ & 86 & $54.1[46.3-61.9]$ & 4 & $2.5[0.1-5.0]$ & 8 & $5.0[1.6-8.5]$ & 85 & $53.8[45.9-61.7]$ & 58 & 36.9 [29.3-44.6] \\
\hline $40+$ & 49 & $48.0[38.2-57.9]$ & 2 & 2. $0[0.8-4.7]$ & 2 & $2.0[0.8-4.7]$ & 63 & $60.4[50.7-70.1]$ & 31 & $31.3[22.0-40.6]$ \\
\hline \multicolumn{11}{|l|}{ Age group 2} \\
\hline $15-24$ & 377 & 46.2 [42.8-49.6] & 18 & $2.2[1.2-3.2]$ & 9 & $1.1[0.4-1.8]$ & 262 & $30.2[27.0-33.3]$ & 154 & $19.3[16.6-22.0]$ \\
\hline $25+$ & 631 & $54.5[51.6-57.4]$ & 32 & $2.8[1.8-3.7]$ & 18 & $1.6[0.8-2.3]$ & 586 & 49.8 [46.9-52.7] & 374 & $33.3[30.5-36.0]$ \\
\hline \multicolumn{11}{|l|}{ Current marital status } \\
\hline Single & 629 & 49.8 [47.0-52.6] & 28 & $2.2[1.4-3.0]$ & 17 & $1.4[0.7-2.0]$ & 495 & 37.5 [34.9-40.2] & 314 & $25.4[23.0-27.8]$ \\
\hline Married/cohabitating & 12 & $63.2[39.3-87.0]$ & 1 & $5.3[0.1-16.3]$ & 1 & $5.3[0.0-16.3]$ & 9 & $42.1[17.7-66.6]$ & 7 & 38.9 [13.9-63.8] \\
\hline Divorced/Separated & 319 & 53.7 [49.7-57.7] & 17 & $2.9[1.5-4.2]$ & 8 & $1.4[0.4-2.3]$ & 285 & $47.3[43.2-51.3]$ & 172 & $30.0[26.3-33.8]$ \\
\hline Widow & 50 & 49.5 [39.6-59.4] & 4 & $3.9[0.1-7.8]$ & 2 & $2.0[0.0-4.7]$ & 59 & 59.4 [49.7-69.1] & 35 & $35.7[26.1-45.4]$ \\
\hline \multicolumn{11}{|l|}{ Province } \\
\hline East & 320 & $49.6[45.7-53.5]$ & 17 & $2.6[1.4-3.9]$ & 12 & $1.9[0.8-2.9]$ & 243 & 36.3 [32.6-40.0] & 136 & $21.6[18.4-24.8]$ \\
\hline Kigali city & 146 & $49.8[44.1-55.6]$ & 8 & $2.7[0.9-4.6]$ & 2 & $0.7[0.3-1.6]$ & 157 & $54.3[48.5-60.0]$ & 102 & $35.7[30.1-41.2]$ \\
\hline North & 172 & $44.2[39.3-49.2]$ & 7 & $1.8[0.5-3.1]$ & 6 & $1.5[0.3-2.8]$ & 143 & $34.8[30.0-39.6]$ & 84 & 21.7 [17.6-25.8] \\
\hline West & 190 & $58.6[53.3-64.0]$ & 10 & $3.1[1.2-5.0]$ & 5 & $1.5[0.2-2.9]$ & 147 & 44.4 [39.0-49.9] & 102 & $32.6[27.4-37.8]$ \\
\hline South & 182 & $55.8[50.4-61.2]$ & 8 & $2.5[0.8-4.2]$ & 3 & $0.9[0.1-2.0]$ & 158 & $46.3[40.8-51.7]$ & 104 & 33.6 [28.3-38.8] \\
\hline \multicolumn{11}{|l|}{ Hotspot type } \\
\hline Street-based & 327 & $52.3[48.4-56.2]$ & 11 & $1.8[0.7-2.8]$ & 4 & $0.6[0.0-1.3]$ & 267 & $41.2[37.3-45.1]$ & 166 & $27.5[23.9-31.1]$ \\
\hline Venue-based & 683 & $50.5[47.8-53.2]$ & 39 & $2.9[2.0-3.8]$ & 24 & $1.8[1.1-2.5]$ & 581 & $41.8[39.2-44.5]$ & 362 & 27.4 [25.0-29.8] \\
\hline \multicolumn{11}{|l|}{ Level of education } \\
\hline None & 234 & $66.3[61.3-71.2]$ & 9 & $2.6[0.9-4.2]$ & 7 & $2.0[0.5-3.4]$ & 184 & $52.6[47.3-57.8]$ & 135 & $35.7[34.5-44.9]$ \\
\hline Primary & 639 & $51.9[49.1-54.7]$ & 32 & $2.6[1.7-3.5]$ & 16 & $1.3[0.7-1.9]$ & 517 & $42.1[39.3-44.9]$ & 333 & $27.7[25.1-30.2]$ \\
\hline Secondary/Higher & 137 & 34.9 [30.1-39.6] & 9 & $2.3[0.8-3.8]$ & 5 & $1.3[0.2-2.4]$ & 118 & 30.3 [25.7-34.9] & 60 & 15.7 [12.0-19.4] \\
\hline \multicolumn{11}{|l|}{ Religion } \\
\hline Catholic & 388 & $50.1[46.5-53.6]$ & 19 & $2.5[1.4-3.5]$ & 13 & $1.7[0.8-2.6]$ & 327 & $41.8[38.3-45.3]$ & 207 & $27.3[24.1-30.5]$ \\
\hline Protestant & 311 & $53.3[49.3-57.4]$ & 13 & $2.2[1.0-3.4]$ & 10 & $1.7[0.7-2.8]$ & 249 & $40.1[36.1-44.1]$ & 152 & $26.7[23.1-30.4]$ \\
\hline Muslin & 80 & $48.8[41.0-56.5]$ & 3 & $1.8[0.2-3.9]$ & 1 & $0.6[0.0-1.8]$ & 67 & $42.1[34.4-49.7]$ & 50 & $31.7[24.3-39.0]$ \\
\hline Adventist & 93 & $50.0[42.7-57.3]$ & 6 & $3.2[0.7-5.8]$ & 1 & $0.5[0.0-1.6]$ & 86 & $42.7[35.5-50.0]$ & 43 & $24.6[18.1-31.0]$ \\
\hline Traditional/Other/No religion & 138 & $51.3[45.3-57.3]$ & 9 & $3.4[1.2-5.5]$ & 3 & $1.1[0.0-2.4]$ & 119 & $43.7[37.7-49.6]$ & 76 & $28.7[23.2-34.2]$ \\
\hline \multicolumn{11}{|l|}{ Had children } \\
\hline Yes & 826 & $51.4[49.0-53.9]$ & 44 & $2.7[1.9-3.5]$ & 23 & $1.4[0.8-2.0]$ & 718 & $43.7[41.3-46.2]$ & 444 & $28.4[26.2-30.7]$ \\
\hline No & 184 & $49.6[44.5-54.7]$ & 6 & $1.6[0.3-2.9]$ & 5 & $1.4[0.2-2.5]$ & 130 & $32.6[27.8-37.4]$ & 84 & $23.1[18.8-27.5]$ \\
\hline \multicolumn{11}{|l|}{ Occupation } \\
\hline Sex work only & 701 & $52.1[49.4-54.8]$ & 37 & $2.8[1.9-3.6]$ & 24 & $1.8[1.1-2.5]$ & 591 & $42.9[40.2-45.5]$ & 366 & $28.9[25.5-30.3]$ \\
\hline Sex work with additional & 309 & $48.9[45.0-52.8]$ & 13 & $2.1[0.9-3.2]$ & 4 & $0.6[0.0-1.3]$ & 257 & $39.0[35.2-42.8]$ & 162 & $26.4[22.9-29.9]$ \\
\hline
\end{tabular}


Table 2 Syphilis, HBV, HCV and HIV prevalence and HIV co-infection among FSW in Rwanda, 2015 (Continued)

\begin{tabular}{llllllllllll}
\hline Duration of sex work & & & & & & & & \\
$0-5$ & 495 & $47.8[44.7-50.8]$ & 22 & $2.1[1.2-3.0]$ & 12 & $1.2[0.5-1.8]$ & 347 & $33.7[30.8-36.6]$ & 220 & $21.7[19.2-24.3]$ \\
$6-15$ & 406 & $54.9[51.3-58.5]$ & 25 & $3.4[2.1-4.7]$ & 10 & $1.4[0.5-2.2]$ & 352 & $47.8[44.1-51.4]$ & 233 & $32.6[29.2-36.1]$ \\
$16+$ & 89 & $56.0[48.2-63.8]$ & 3 & $1.9[0.3-4.0]$ & 6 & $3.8[0.8-6.8]$ & 97 & $61.0[53.3-68.7]$ & 60 & $38.2[30.5-45.9]$ \\
\hline
\end{tabular}

In multiple logistic regression, FSWs with the following characteristics were positively associated with syphilis/HIV co-infection: age 25 years and older $(\mathrm{aOR}=1.82$ [95\% CI:1.33-2.50]) compared to those less than 25 years old, having had a genital sore in the last 12 months $(\mathrm{aOR}=1.34[95 \% \mathrm{CI}: 1.05-1.71])$ compared to FSWs without STI symptoms, and having HBsAg-positive test $(\mathrm{aOR}=2.09[1.08-4.08])$ compared to FSWs with HBsAg-negative test (Table 3).

\section{Discussion}

FSWs are among key drivers of HIV and other STIs in many countries. The current study was conducted among self-identified FSWs at different hot spots in the country to characterize the scope of this public health problem in Rwanda.

Two important findings resulted from this survey. Syphilis and HIV prevalence among FSWs in Rwanda was very high and increased with age and the duration of sex work. FSWs with any positive test were transferred to the nearest health facility or the health facility of choice for appropriate clinical care.

Overall HBV and HCV prevalence among FSWs in Rwanda was low ( $<5 \%$ each). Older FSWs, secondary or higher education, STIs symptoms, and HBV infection are independent predictors of HIV and syphilis coinfection.

Compared to the prevalence of the general population (3.0\%) [6], the HIV prevalence among FSWs (42.9\%) of our study was more than 14 times higher; and it is among the highest reported to date in Africa [3]. In the Rwandan context, sex work is illegal and often considered a shameful activity, some among FSWs operate in hidden unsecured places due to poor socio-economic conditions. This high HIV prevalence may be attributed to inconsistency in condom use, lack of negotiating power with clients over condom use, sexual violence and access to HIV care and treatment. In the current study, a proportion of $81.2 \%$ among FSWs had children with a risk of vertical transmission. In sub-Saharan Africa, in Togo FSWs had higher HIV prevalence (76.7\%) [25]; For unknown reasons, other countries had lower HIV prevalence. It was $32.2 \%$ in Kenya, $15.7 \%$ in Uganda, 3.5\% in Democratic Republic of Congo [25].

The overall prevalence of syphilis of our study was $(51.1 \%)$ while it was $1.0 \%$ in the general population of
Rwanda [26]. Although the current prevalence of syphilis in our study could be current or past infection, it is still very high. Due to the high prevalence of HIV in the current study $(42.9 \%)$, it is not surprising to find a similar prevalence of syphilis. The prevalence of syphilis among FSWs in our study was higher compared to the prevalence of syphilis in many other countries. For instance it was 3.3\% in Kisumu, Kenya [10], 21.0\% in Kampala, Uganda [3]. However, the prevalence of syphilis among FSWs in Rwanda was similar to the prevalence of syphilis among FSWs in in Addis Ababa, Ethiopia 52.4\% [12].

HIV and syphilis have similar modes of transmission. The burden of HIV and syphilis among FSWs is considerable in Rwanda; it could contribute to high morbidity and mortality rates in this key population. The prevalence of syphilis and HIV co-infection was high (27.4\%). In terms of proportion of co-infection, in Nepal, the proportion of syphilis infection among HIV-positive FSWs was $31.0 \%$ [18], it was $69.2 \%$ in our study. In Addis Ababa the proportion of HIV among syphilis-positive FSWs recruited in STIs clinic was 85.1\% [12].

Older age was identified as an associated factor of high HIV and syphilis co-infection; the same factor was identified in prevalence of syphilis in a Chinese study [21].

Secondary or higher education was negatively associated with higher prevalence of HIV and syphilis coinfection $(\mathrm{aOR}=0.50)$. The assumption behind this finding may be the fact that FSWs with secondary and higher education could have additional occupation to the sex work, thus reduce the risk of exposure. In addition, they may have possibility to access prevention programmes, and could have power for condom use negotiation. They could also access to STIs treatment compared to illiterate FSWs. In China, researchers also found that years of education was a protective factor of STIs [21].

A recent history of genital sores was identified as an independent variable positively associated with high HIV and syphilis co-infection $(\mathrm{aOR}=1.34$ [95\% CI: $1.05-$ 1.71]). Ulcerative STIs facilitate HIV and other blood borne diseases transmission and acquisition. The same observation regarding HIV infection risk factors was found in India [21].

The prevalence of HBV among FSWs in our study was lower (2.4\%). There is no previous estimated prevalence 
Table 3 Factors associated with HIV and syphilis co-infection among FSWs in Rwanda, 2015

\begin{tabular}{|c|c|c|c|c|c|c|}
\hline \multirow[t]{2}{*}{ Characteristics } & \multicolumn{3}{|c|}{ Bivariable } & \multicolumn{3}{|c|}{ Multivariable } \\
\hline & $\overline{O R}$ & $95 \% \mathrm{Cl}$ & $p$-value & $\mathrm{aOR}^{\mathrm{a}}$ & $95 \% \mathrm{Cl}$ & $p$-value \\
\hline \multicolumn{7}{|l|}{ Age group } \\
\hline $15-24$ years & 1.00 & & & 1.00 & & \\
\hline$\geq 25$ years & 2.09 & $1.68-2.56$ & 0.00 & 1.82 & $1.33-2.50$ & 0.00 \\
\hline \multicolumn{7}{|l|}{ Marital status } \\
\hline Never married & 1.00 & & & 1.00 & & \\
\hline Ever married & 1.32 & $1.08-1.63$ & 0.01 & 1.01 & $0.78-1.32$ & 0.09 \\
\hline \multicolumn{7}{|l|}{ Education } \\
\hline None/primary & 1.00 & & & 1.00 & & \\
\hline Secondary and higher & 0.50 & $0.36-0.66$ & 0.00 & 0.50 & $0.36-0.69$ & 0.00 \\
\hline \multicolumn{7}{|l|}{ Occupation } \\
\hline Sex work with additional occupation & 1.00 & & & & & \\
\hline Sex work only & 1.08 & $0.87-1.34$ & 0.50 & & & \\
\hline \multicolumn{7}{|l|}{ Duration of sex work } \\
\hline$<5$ years & 1.00 & & & 1.00 & & \\
\hline$\geq 5$ years & 1.82 & $1.49-2.40$ & 0.00 & 1.22 & $0.92-1.61$ & 0.39 \\
\hline \multicolumn{7}{|l|}{ Having children } \\
\hline Doesn't & 1.00 & & & 1.00 & & \\
\hline Had children & 1.32 & $1.01-1.72$ & 0.04 & 1.03 & $0.73-1.46$ & 0.85 \\
\hline \multicolumn{7}{|l|}{ Recruitment based } \\
\hline Venue based & 1.00 & & & & & \\
\hline Street based & 1.00 & $0.81-1.25$ & 0.97 & & & \\
\hline \multicolumn{7}{|l|}{ Consistent condom use in the last 30 days } \\
\hline Consistent & 1.00 & & & & & \\
\hline Not consistent & 1.00 & $0.82-1.33$ & 1.00 & & & \\
\hline \multicolumn{7}{|l|}{ Drunk alcohol every day in the last 4 weeks } \\
\hline Drunk alcohol & 1.00 & & & & & \\
\hline Didn't drink alcohol & 0.88 & $0.71-1.08$ & 0.23 & & & \\
\hline \multicolumn{7}{|l|}{ HIV Comprehensive knowledge } \\
\hline Had not & 1.00 & & & & & \\
\hline $\mathrm{Had}$ & 1.06 & $0.86-1.31$ & 0.58 & & & \\
\hline \multicolumn{7}{|l|}{ Had genital sore in last 12 months } \\
\hline Had not & 1.00 & & & 1.00 & & \\
\hline $\mathrm{Had}$ & 1.32 & $1.08-1.63$ & 0.01 & 1.34 & $1.05-1.71$ & 0.02 \\
\hline \multicolumn{7}{|l|}{ Anal sex } \\
\hline Had not & 1.00 & & & & & \\
\hline Had & 1.00 & $0.69-1.44$ & 0.99 & & & \\
\hline \multicolumn{7}{|l|}{ HBV positive test } \\
\hline Negative & 1.00 & & & 1.00 & & \\
\hline Positive & 2.13 & $1.21-3.75$ & 0.01 & 2.09 & $1.08-4.06$ & 0.03 \\
\hline \multicolumn{7}{|l|}{ HCV positive test } \\
\hline Negative & 1.00 & & & & & \\
\hline Positive & 1.26 & $0.57-2.80$ & 0.57 & & & \\
\hline
\end{tabular}

${ }^{\mathrm{a}} \mathrm{OR}=$ Adjusted odds ratio

${ }^{\mathrm{b}} \mathrm{HIV}$ Comprehensive knowledge was defined as knowing HIV prevention methods and rejecting misconception of HIV transmission Only significant values ( $p$-value) are in bold 
of HBV in the general population or in any other key population including FSWs in Rwanda. HBV prevalence was $8.8 \%$ in Brazil [10] whereas in sub-Saharan African countries, for instance in Nigeria, it was $17.1 \%$ [17] and it was $13.3 \%$ in Nairobi, Kenya [25].

The prevalence of $\mathrm{HCV}$ was $1.1 \%$ in our study. $\mathrm{HCV}$ is not a high burden among FSWs in Rwanda compared to HIV (42.9\%) and syphilis (51.1\%). Few data on this area are available. However, a study on HCV and HBV conducted among health workers in a tertiary hospital reveled that the prevalence of HBsAg-positive and antiHCV-positive was respectively $2.9 \%$ and $1.3 \%$ [27]. Another study conducted among HIV-positive patients in Kigali, Rwanda, showed that HBsAg-positive and antiHCV-positive was respectively $5.2 \%$ and $5.7 \%$ [28]. HCV prevalence was similar with the prevalence found in Nairobi, Kenya $0.8 \%$ [18], but much lower than the estimated prevalence of HCV in Brazil (23.1\%) [10].

Several limitations were encountered in our study. First home-based FSWs and those operating inside hotels were underrepresented in the study because the recruitment was focused on streets and around venues where FSW are found such as hotels, cabarets and night clubs. Second, venues with FSWs less than five per day were excluded by the sampling methodology. Third, specific sexual practices and behaviors and other risk factors associated with STIs among sex workers were not explored in depth. Fourth, the syphilis prevalence reported in this study was first performed using SD Bioline rapid test; confirmed with RPR test. Due to budget constraints a confirmatory test using TPHA test was not performed.

\section{Conclusion}

Based on our findings, we conclude that HIV and syphilis prevalence are very high among FSWs in Rwanda. A strong specific prevention program to avert HIV infection and other STIs transmission to their clients; and proper treatment should be reinforced. Current programs sponsored by the Ministry of Health can help to fight against stigma and discrimination against sex workers - specifically, promoting outreach approach to test and treat all HIV FSWs; testing and treating other STIs among FSWs using rapid tests in their community and improve prevention program for HIV and other STIs reduction. Strengthening HIV and STIs prevention program including condom distribution in the community, training peer educators to be involved in program implementation and linking FSW's community to care providers in confidential way. Organizing a regular campaign for HIV and STIs testing and treatment in the community. Supporting income generating activities and regular mentorship in order to improve the poor socio-economic status of most of FSWs.

\section{Abbreviations}

Ab: Antibody; Ag: Antigen; AIDS: Acquired Immunodeficiency Syndrome; aOR: Adjusted Odds Ratio; CDC: Centre for disease control and prevention; Cl: Confidence Interval; ELISA or EIA: Enzyme-Linked Immuno-Sorbent Assay; FSW: Female sex worker; HBsAg: Hepatitis B surface antigen; HBV: Hepatitis B Virus; HCV: Hepatitis C virus; HIV: Human immunodeficiency virus;

IQR: Interquartile range; NRL: National Reference Laboratory; OR: Odds Ratio; PDA: Personal digital assistant; PSU: Primary Sampling Unit; RBC: Rwanda Biomedical Center; RNEC: Rwanda National Ethics Committee; RPR: Rapid plasma reagin; SD: Standard Diagnostic; STI: Sexually Transmitted Infection; TPHA: Treponema pallidum haemaglutination assay; VDT: Venue-day-time; WHO: World Health Organization

\section{Acknowledgements}

We acknowledge the contribution of the United States Center for Disease Control and Prevention, the Government of Rwanda and other partners for their financial and technical support. We are recognizing the female sex workers behavior surveillance survey technical working group, participants in the survey, key informants, local leaders and selected health centers staff for their technical support.

\section{Author contributions}

MM had full access to all of the data in the study, to conception and design, acquisition of data, analysis and interpretation of data. MM and DS worked on the integrity of the data, the accuracy of the data analysis. MM and SD supervised data collection; MM, DS, JN and DR performed statistical analysis; all authors contributed to data review and interpretation. MM and JN drafted the manuscript; DR and LN conducted a critical revision of the manuscript for important intellectual content. MM contributed to fund mobilization, administrative and technical support for the survey. All authors read and approved the final manuscript for publication.

\section{Funding}

The survey was funded by the Government of Rwanda and CDC.

\section{Availability of data and materials}

The dataset and materials source of the current manuscript are not publically available, but are available from the Rwanda Biomedical Center on reasonable request.

Ethics approval and consent to participate

All interviews were conducted in private locations to ensure confidentiality. A unique anonymous study identifier number was assigned to every participant. Verbal voluntary informed consent was obtained from participants. The study was reviewed and approved by the Rwanda National Ethics Committee (Approval No: RNEC: 029/RNEC/2012).

Consent for publication

Not applicable.

Competing interests

The authors declare that they have no competing interests.

\section{Publisher's Note}

Springer Nature remains neutral with regard to jurisdictional claims in published maps and institutional affiliations.

\section{Author details}

${ }^{1}$ Rwanda Biomedical Centre, Ministry of Health, P. O. Box, 7162 Kigali, Rwanda. ${ }^{2}$ University of Rwanda, College of Medicine and Health Sciences, School of Public Health, Kigali, Rwanda. ${ }^{3}$ Institute of Human Virology and Division of Infectious Diseases, University of Maryland School of Medicine, Baltimore, MD, USA. 
Received: 11 January 2017 Accepted: 20 July 2017

Published online: 28 July 2017

\section{References}

1. World Health Organization. Baseline report on global sexually transmitted infection surveillance 2012

2. Shannon K, Strathdee SA, Goldenberg SM, et al. Global epidemiology of HIV among female sex workers: influence of structural determinants. Lancet. 2015;385:55-71.

3. Deanna Kerrigan, Andrea Wirtz, Stefan Baral. The Global HIV Epidemics among Sex Workers. World Bank report, 2013

4. Ngugi EN, Roth E, Mastin T, et al. Female sex workers in Africa: Epidemiology overview, data gaps, ways forward. Journal of Social Aspects of HIV/AIDS. 2012;9(3):148-53.

5. Papworth E, Ceesay N, An L, et al. Epidemiology of HIV among female sex workers, their clients, men who have sex with men and people who inject drugs in West and Central Africa. Journal of the International AIDS Society. 2013;16(Suppl 3):18751.

6. National Institute of Statistics of Rwanda (NISR) [Rwanda], Ministry of Health (MOH) [Rwanda], and ICF International. Rwanda Demographic and Health Survey 2014-15. Rockville, Maryland, USA: NISR, MOH, and ICF International; 2015.

7. Braunstein SL, Ingabire CM, Kestelyn $\mathrm{E}$, et al. High Human Immunodeficiency Virus Incidence in a Cohort of Rwandan Female Sex Workers. Sex Transm Dis. 2011;38(5):385-94.

8. National Institute of Statistics of Rwanda (NISR) [Rwanda], Ministry of Health $(\mathrm{MOH})$ [Rwanda], and ICF International. Rwanda Demographic and Health Survey 2010. Calverton, Maryland, USA: NISR, MOH, and ICF International; 2011.

9. Kriitmaa K, Testa A, Osman M, et al. HIV prevalence and characteristics of sex work among female sex workers in Hargeisa, Somaliland. Somalia. AIDS. 2010;24(suppl 2):S61-7.

10. Vandenhoudt HM, Langat L, Menten J, Odongo F, Oswago S, et al. Prevalence of HIV and Other Sexually Transmitted Infections among Female Sex Workers in Kisumu, Western Kenya, 1997 and 2008. PLoS ONE. 2013;8(1):e54953. doi:10.1371/journal.pone.0054953.

11. Vandepitte J, Bukenya J, Weiss HA, et al. HIV and Other Sexually Transmitted Infections in a Cohort of Women Involved in High-Risk Sexual Behavior in Kampala. Uganda. Sex Transm Dis. 2011:38(4):316-23.

12. Aklilu M, Messele T, Tsegaye A, et al. Factors associated with HIV-1 infection among sex workers of Addis Ababa, Ethiopia. AIDS. 2001;15:87-96.

13. World Health Organization. Hepatitis C. 2014 [cited 20 September 2016]. (http://www.who.int/mediacentre/factsheets/fs164/en/)

14. Lu W, Tang W. Wang Lan et al. The HIV, Syphilis, and HCV Epidemics Among Female Sex Workers in China: Results From a Serial Cross-Sectional Study Between 2008 and 2012. Clinical Infectious Dis. 2014;59(1):1-9.

15. Chen Y, Shen Z, Morano JP, et al. Bridging the Epidemic: A Comprehensive Analysis of Prevalence and Correlates of HIV, Hepatitis C, and Syphilis, and Infection among Female Sex Workers in Guangxi Province, China. PLoS ONE. 2015;10(2):e0115311. doi:10.1371/journal.pone.0115311.

16. Praseeda DS, Anuradha D, JAYANTHI SS. A Study on the HBV and the HCV Infections in Female Sex Workers and their Co-Infection with HIV. J Clin and Diagn Res. 2013;7(2):234-7.

17. Forbi JC, Onyemauwa N, Gyar SD, et al. High prevalence of hepatitis B virus among female sex workers in Nigeria. Rev. Inst. Med. trop. S. Paulo. 2008; 50(4):219-21.

18. Collis TK, Celum CL. The clinical manifestations and treatment of sexually transmitted diseases in human immunodeficiency virus-positive men Clin Infect Dis. 2001;32:611-22.

19. Greenstone CL, Saint S, Moseley RH. A Hand-Carried Diagnosis. N Engl J Med. 2007:356:2407-11.

20. Silverman JG, Decker MR, Gupta J, et al. Syphilis and Hepatitis B Co-infection among HIV-Infected, Sex-Traffi cked Women and Girls, Nepal. Retrieved from http://wwwnc.cdc.gov/eid/article/14/6/pdfs/08-0090.pdf.

21. Li Y, Detels R, Lin P, et al. Prevalence of HIV and STIs and Associated Risk Factors Among Female Sex Workers in Guangdong Province, China. J Acquir Immune Defic Syndr. 2010;53:S48-53.

22. Walker TD. Emmanuel Musabeyezu2,3. Hepatitis B in Rwanda: Closing the gaps to end an epidemic. Rwanda Journal Series F: Medicine and Health Sciences. 2015;2(1):76-9.
23. Barth RE, Huijgen Q, Taljaard J, et al. Hepatitis B/C and HIV in sub-Saharan Africa: an association between highly prevalent infectious diseases. A syst rev and meta-analysis. International Journal of Infectious Diseases. 2010;14:e1024-31.

24. Muhib FB, Lin SL, Stueve A et al. A venue-based method for sampling Hard-to-Reach Populations. Public health reports 2001; Supplement 1. (116)

25. Kerubo G, Khamadi S, Okoth V, et al. Hepatitis B, Hepatitis C and HIV-1 Coinfection in Two Informal Urban Settlements in Nairobi. Kenya. PLoS ONE. 2015;10(6):e0129247. doi:10.1371/journal.pone.0129247.

26. Mutagoma M, Remera E, Sebuhoro D et al. The Prevalence of Syphilis Infection and Its Associated Factors in the General Population of Rwanda: A National Household-Based Survey. Journal of Sexually Transmitted Diseases 2016;doi.org/10.1155/2016/4980417

27. Kateera F, Timothy D. Walkerb TD, Mutesa L. Hepatitis B and C seroprevalence among health care workers in a tertiary hospital in Rwanda. Trans R Soc Trop Med Hyg 2015; 109:203-208

28. Rusine J, Ondoa P, Asiimwe-Kateera B, et al. High Seroprevalence of HBV and HCV Infection in HIV-Infected Adults in Kigali. Rwanda. PLOS ONE. 2013;8(5):e63303. doi:10.1371/journal.pone.0063303.

\section{Submit your next manuscript to BioMed Central and we will help you at every step:}

- We accept pre-submission inquiries

- Our selector tool helps you to find the most relevant journal

- We provide round the clock customer support

- Convenient online submission

- Thorough peer review

- Inclusion in PubMed and all major indexing services

- Maximum visibility for your research

Submit your manuscript at www.biomedcentral.com/submit
Biomed Central 